\title{
Designing Social Memory Artifacts in a Smart Home
}

Jasmine Jones

School of Information

University of Michigan

Ann Arbor, MI

jazzij@umich.edu
Permission to make digital or hard copies of all or part of this work for personal or classroom use is granted without fee provided that copies are not made or distributed for profit or commercial

advantage and that copies bear this notice and the full citation on the first page. Copyrights for components of this work owned by others than ACM must be honored. Abstracting with credit is permitted. To copy otherwise, or republish, to post on servers or to redistribute to lists, requires prior specific permission and/or a fee. Request permissions from Permissions@acm.org.

GROUP '16, November 13-16, 2016, Sanibel Island, FL, USA

(c) 2016 ACM. ISBN 978-1-4503-4276-6/16/11 ...\$15.00

DOI: http://dx.doi.org/10.1145/2957276.2997021

\begin{abstract}
Memory is shaped by the media in which it is communicated (van Dijck, 2007). In a world where people live enmeshed with computing technologies, there are myriad opportunities to enrich and enhance everyday life with new kinds of memory. In my dissertation research, I employ a mixed methods interpretivist approach to investigate how people relate to and revisit memories of their past, how families collectively interact with shared memory, and how pervasive "ubicomp" technologies can be designed to support and enhance the social activities of sharing family memory across generations.
\end{abstract}

\section{Author Keywords}

Memory; pervasive computing; family; design; time

\section{Introduction}

There has been a great deal of interest from the HCI and CSCW communities in designing technologies for the home and for families, with memory-related topics ranging from understanding why people cherish idiosyncratic objects (Golsteijn et al., 2012), to designing "technology heirlooms" that afford longlasting durability and high value polish to digital memorabilia (Odom et al., 2012). Most of the work in this area primarily considers autobiographical memory which is the memory a person has of their own experiences. 
Shifting to Collective Memory

Even when considering individual, personal memory, it is quite social in nature. In a social frame, activities of memory are understood to take place 1 ) with social materials, 2) within social contexts, and 3) in response to social cues (Mitzal, 2003; Kirk \& Sellen, 2010). Further, individuals are social beings, referencing social identities, and using languages and symbols derived from the groups in which one is a member. Yet, memories that are shared also exist and take shape beyond any one individual's ability to remember (for example, war memorials). As these shared memories become the foundation of a group identity, they are referred to as collective memory (Zerubavel, 1996). In my work, I examine "family memory," the collective memory of the family passed from one generation to the next.

\section{Family Memory in a Smart Home}

Considering the home as a pervasive computing environment, I became interested in how technologies in the home could facilitate interacting with a family's collective memory. Family memory is one of the most fundamental influences on a person's identity and relation to their social world, and serves to unite related individuals into a cohesive social unit

(Zerubavel, 1996). However, it is also the site of potential conflict with issues such as family secrets, generational divides, and feuds influencing how people view and engage with the past. Thus, technologies designed for family memory are not just about preserving the past for future generations, but also for negotiating which version of the past to convey.

Following an interprevist approach, using qualitative and design research methods, I aim in my dissertation to understand the current sociotechnical context of family memory and explore solutions that address the challenges in this space.

\section{Understanding Family Collective Memory}

Through a series of ethnographic studies, I am conceptualizing how family members interact around shared memories. In my work, I approach memory sharing as an ongoing (re)construction and

(re)interpretation of the past, and focus on how families might use physical artifacts to facilitate creating, sharing, and revisiting their shared memories.

The work of family memory keepers

To delve into this topic, I conducted in-depth interviews with family memory "keepers," people, typically in an older generation, who assume primary responsibility in a family for ensuring continuity of family history and lore. In these interviews I sought to understand what constituted the "memory" that today's families kept, and how physical and digital objects played a role in passing these memories to the next generation.

Family memory keepers viewed memory artifacts as important sources of memory as well as tools to facilitate the exchange of memory narratives. Memory keepers reported much of their effort being spent in finding stories about the family-often to get answers to unexplained questions or to fill in holes in existing narratives. Artifacts could serve as subtle signals that a story existed even if it had been hidden or forgotten. Memory keepers also had to restore family stories that that seemed incomplete or incorrect. In these cases, artifacts acted as anchors that could ground and give a sense of realness and personality to stories and historical facts. 
However, at times there were different perspectives on a person, conflicting accounts about an event, or discrepancies between family records and public records. Artifacts were often sources of conflict in conveying previously unknown or incongruent information. In these cases, memory keepers had to decide how to resolve this contested memory to maintain a cohesive family narrative.

An open question from this work is how memory artifacts could be designed to help family memory keepers with the ongoing challenge of negotiating and resolving contested narratives.

\section{Design at Scale: Engaging with Digital Mementos}

A second issue facing families is the vast difference in scale that exists between a family's physical sentimental artifacts and their digital counterparts. For example, a person might have a small box of mementos from their childhood, or dozens of old photographs featuring their ancestors, but have thousands of digital photos documenting the mundane and important details of their lives. The volume of content that families can collect is unprecedented and can be overwhelming for them to make sense of and use. As technological tools to capture important memories proliferate, it is important also to enable people to curate the content they are generating so it is useful to them for future memory purposes.

Kidkeeper: An illustration of curatorial reluctance I conducted a user study of a toy-like audio capture system for children and parents, named Kidkeeper, developed by my colleague David Merritt (Jones, Merritt \& Ackerman, to appear). Kidkeeper was a fun plaything for children that had a number of features that made it useful for parents in capturing and saving audio-based mementos of their children when they were young. However, in our interviews we learned that, while parents emphasized their desire to have many, highquality mementos of their children, they were unlikely to expend the effort to select the ones they liked and wanted to keep from a large collection. Instead, because of the sheer volume, they would either keep them all (somewhere on a hard drive) or delete them.

This paradoxical reaction reveals a thorny socialtechnical (Ackerman, 2000) design problem for digital mementos. There was a mismatch in our parents' expectations about what services a technological memory artifact should provide (capturing and delivering enjoyable content to them) and the effort they were willing to expend to initialize and maintain such services (i.e. by providing their content preferences). In a memory context, we realized that this was fundamentally an issue of curation.

Unpacking the social-technical problem of curation A great deal of work both in research and in industry has characterized the lack of curation of digital content as both a technical problem and a social problem. Socially, an over-abundance of meaningless content can obscure any valuable artifacts in a collection, leading to devaluation and loss of precious memorabilia (Marshall, Bly, \& Brun-Cottan, 2006). Technically, digital curation is not well supported and existing technology solutions have not been widely adopted.

Yet, a fundamental design assumption of most memory artifacts is that the media content being presented and displayed has been curated somehow and is valuable for the user's recollection. Thus, there is a need for 
systems that somehow encourage users to curate their content or develop ways to automate curation by intuiting what might be sentimental and valuable in a mixed heap of artifacts.

To gain insight on how designers might facilitate the management of large collections of digital mementos in everyday life, I conducted a qualitative analysis of a forum featuring conversations from people struggling to deal with an overabundance of artifacts that had deep personal value (Jones \& Ackerman, to appear).

Participants enacted several "curation regimes" using storage and display areas in their home to organize their artifacts and maximize the attention they were able to pay to them. Importantly, curation for these participants was an ongoing process integrated into how they interacted with and arranged their memory artifacts, rather than a precursor to use. This finding suggests a wealth of opportunities for design in translating the interactive and practical features of physical curation to enhance the curation of digital mementos, while also enabling meaningful use of large amounts of content.

\section{Future: Designing Social Memory Artifacts}

In my current and future work, I am implementing some of the major implications from my previous work on integrating capture, curating large collections of digital mementos, and resolving contested narratives. To explore these issues from a design perspective, my colleagues and I have developed an exploratory prototype called "Storyball". In its basic form, Storyball takes the form of a magic- 8 ball that, when shaken, replays a recorded memory narrative. This application, though simple, opened up a larger design space for revisiting recorded traces of the past. This design space posed a number of challenges not easily answered by current knowledge or solvable with existing approaches of designing for memory.

\section{Resolving Contested Narratives}

Using Storyball as a probe, and also as prototypical artifact, the questions I am investigating are social: "Who has the right to tell a family story encapsulated in one of these artifacts?"; technical: "How can people engage with memory narratives that have multiple versions (or are from multiple people) in a physical object or set of objects?" and temporal: "When is the right time to present and revisit a version of a memory?"

\section{Integrating Curation into Memory Practice}

As a first step towards expanding the interactions people might have with large collections of memories, I am designing form factors for objects which reflect the emotional valence of the narratives they convey. My goal is to add a memory of emotion to artifacts that represent some aspect of the past, making it easier to maintain its full significance when passed on to the next generation. The added context, could also help people decide what to keep and discard.

In future work, I would like design social memory artifacts that incorporate a wide range of digital traces, such as from personal informatics devices, as sources of memory. It is unclear whether such traces by themselves might be useful for reminiscing on the past, however I believe that in aggregate, a collection of data from many varied sources could be pieced together like fragments in a mosaic, with many different angles coming together in a new kind of view of the past. Further, these new kinds of memory may allow us to 
engage with each other and with traces of the past in very different ways that might fundamentally change how people remember.

\section{Acknowledgements}

Special thanks to my PhD advisor, Mark S. Ackerman, my co-author, David Merritt, and the rest of the Social Worlds Research Group for their collaboration and feedback.

\section{References}

1. Ackerman, M. S. (2000). The intellectual challenge of CSCW: the gap between social requirements and technical feasibility. Human-Computer Interaction 15, 2, 179-203.

2. Golsteijn, C., van den Hoven, E., Frohlich, D., \& Sellen, A. (2012). Towards a More Cherishable Digital Object. In Proceedings of the 2012 Conference on Designing Interactive Systems - DIS 12 (pp. 655-664).

3. Kirk, D.S. and Sellen, A. (2010) On human remains. ACM Transactions on Computer-Human Interaction 17, 3, 1-43.

4. Marshall, C. C., Bly, S., \& Brun-Cottan, F. (2006). The long term fate of our digital belongings: Toward a service model for personal archives. In Proceedings of the Archiving Conference (pp. 2530).

5. Misztal, B. (2003) Theories Of Social Remembering. McGraw-Hill International.

6. Jones, J., Ackerman, M.S. (to appear) Curating an Infinite Basement: Understanding how people manage collections of sentimental artifacts. In Proceedings of 2016 Conference on Supporting Group Work, GROUP'16.

7. Jones, J., Merritt, D., Ackerman, M.S. (to appear) Kidkeeper: Design for capturing audio mementos of everyday life for parents of young children. In
Proceedings of 2017 Conference on ComputerSupported Cooperative Work, CSCW'17.

8. Mols, I., Hoven, E. van den, \& Eggen, B. (2014). Making memories. In Proceedings of the 2014 Nordic Conference on Human-Computer Interaction NordiCHI'14 (pp. 256-265).

9. Odom, W., Banks, R., Harper, R., Kirk, D., Lindley, S., \& Sellen, A. (2012). Technology Heirlooms? Considerations for Passing Down and Inheriting Digital Materials. In Proceedings of the 2012 International Conference on Human Factors in Computing Systems - CHI'12 (pp. 337-346).

10. Odom, W., Pierce, J., Stolterman, E., \& Blevis, E. (2009). Understanding why we preserve some things and discard others in the context of interaction design. Proceedings of the 2009 International Conference on Human Factors in Computing Systems - CHI 09, 1053.

11. Oleksik, G., \& Brown, L. M. (2008). Sonic gems: exploring the potential of audio recording as a form of sentimental memory capture. In Proceedings of the 2008 British HCI Group Annual Conference on People and Computers- BCS-HCI '08 (pp. 163172).

12. van Dijck, J. (2007). Mediated Memories in the Digital Age. Stanford University Press.

13. Van Erve, D., Vos, G.-W., van den Hoven, E., and Frohlich, D. (2011) Cueing the past. Proceedings of the Second Conference on Creativity and Innovation in Design - DESIRE '11, 335.

14. Zerubavel, E. (1996). Social memories: Steps to a sociology of the past. Qualitative Sociology, 19(3), 283-299. 